\title{
Design of Experiments for Coating Process of Valsartan and Pravastatin Fixed-dose Combination Tablet
}

\author{
Kangmin Kim and Jae Seon Kang \\ College of Pharmacy, Kyungsung University, Busan 608-736, KOREA.
}

\begin{abstract}
Aim of work: The purpose of this study was to prepare the ranges of critical process parameters (CPP) (spray rate, pan speed, and inlet temperature) in the coating process of valsartan and pravastatin fixed-dose combination (FDC) tablets using design of experiment (DoE). A central composite face-centered DoE with three center points was employed in this study. Method: Valsartan and pravastatin FDC tablets were manufactured by wet granulation, drying, sieving, blending, tableting and coating. For the coating process, 3-factorial (spray rate, pan speed and inlet temperature), 4-level (defect, coating efficiency, disintegration time and dissolution), and 1-center $(n=3)$ points as critical quality attributes (CQAs) were applied for the DoE batch using Design Expert Software. Results: Spray rate and inlet temperature were an important factor in the defect and coating efficiency results $(p<0.05)$. The results indicated that spray rate $\left(4.1 \mathrm{~g} / \mathrm{min}\right.$ ), pan speed (from 18 to $23 \mathrm{rpm}$ ), and inlet temperature (from 63 to $67^{\circ} \mathrm{C}$ ) for coating process were optimal for valsartan and pravastatin FDC tablets. Conclusion: These studies illustrated that coating process spaces can be defined that COAs based on levels of risk (defects, coating efficiency, disintegration and dissolution). It can be concluded that the wide process ranges of operation leading to high quality (low defect and coating efficiency) for the CPPs of coating process were successfully observed by the DoE approach.
\end{abstract}

Key words: Valsartan, Pravastatin, Quality by design, Design of experiment, Coating.

\section{INTRODUCTION}

Tablet film coating is a widely used to improve the tablet having the sensitivity from light, temperature and moisture for functional supplements. ${ }^{1}$ Tablet film coating is also used to control the drug release of modified release tablet. ${ }^{2}$ Typically, coating is the last step in the manufacturing process before the product is packaged. The effect of coating process parameters and the cause of variability with factors such as equipment, conditions, and compositions is to be considered to produce the products of high quality. ${ }^{3}$ The most commonly technique for coating is manufactured by spray method using nozzles in a side-vented pan coater which is rapidly and continuously dried. The coating tablet made by side-vented pan coater must be satisfactorily smooth, uniform and adhesion of tablet and chemical stability of drugs. ${ }^{4}$

Generally, film-coating formulations and coating process parameters such as pan speed, inlet air flow rate, air pressure, air temperature, and flow rate are well understood. ${ }^{5}$ The international conference on harmonization $(\mathrm{ICH})$ pharmaceutical development Q8 guideline is also introduced to quality-by-design (QbD) studies for critical material attributes (CMA) and CPP affecting CQA on the film coating process. ${ }^{6}$ If the film coating materials such as opadry ${ }^{\circledR}$ is carefully managed by the manufacturer, it is expected that the influence of CMAs for coating
Submission Date: 21-08-2016; Revision Date: 26-09-2016; Accepted Date: 02-10-2016

DOI: 10.5530/ijper.51.1.17 Correspondence: Kangmin Kim,

College of Pharmacy, Kyungsung University, Busan-Korea

Email: kkij79@hanmail.net Ph.no: +82-10-3266-2687

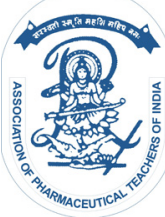

www.ijper.org 
ingredients can be evaluated as low risk in the initial risk assessment. ${ }^{7}$ In this case, CPPs affecting CQAs on the coating process may be studied using DoE. For example, CPPs of tablet temperature, pan speed, and spray rate affecting commonly in CQAs on the coating process may be required to study for the reduced risk. ${ }^{7}$

For the DoE application of coating process, CPPs affecting CQAs are projected using experience, such as operational parameters (including mixing time, mixing speed, and spray rate of coating suspension, atomization pressure, etc) and possible product outcome (including defect, coating efficiency, disintegration, and dissolution). ${ }^{8}$ In the present research, the core tablet was used to prepare valsartan and pravastatin FDC tablet. The effects of spray rate, pan speed, and inlet temperature on defect, coating efficiency, disintegration, and dissolution of a valsartan and pravastatin FDC tablet were evaluated by a DoE approach. A central composite face-centered for response surface design was used and seventeen experimental runs were studied. The object of this study was to optimize an application of an immediate release aqueous film coating system, Opadry ${ }^{\circledR} 200$ by the DoE application of CPPs on QbD for the optimal and robust coating process.

\section{MATERIALS AND METHODS}

\section{Chemicals and reagents}

Valsartan and pravastatin were purchased from MSN Laboratories Private Limited (Hyderabad, India) and Hisun Pharmaceutical Co. Ltd. (Zhejiang, China). Microcrystalline cellulose (Vivapur types 101, JRS, Germany), magnesium oxide (Heavy, Tomita, Japan), low-substituted hydroxypropyl cellulose (LH22, Shinetsu, Japan), croscarmellose sodium (Acdisol, FMC biopolymer, Belgium), and magnesium stearate (Hyqual, Mallinckrodt, USA) were used for coating study on tablet. All other chemicals and reagents were of commercially available pharmaceutical grades. The coating materials used aqueous based on the Opadry $200^{\circledR}$ (Colorcon, West Point, USA) coating system. The reference drugs for dissolution used were valsartan $\left(\right.$ Diovan $^{\circledR}$, Novartis Co. Ltd) and pravastatin (Mevalotin ${ }^{\circledR}$, Daiichi Sankyo Co.Ltd).

\section{Preparation of the valsartan and pravastatin FDC tabletfor coating study}

For DoE study of coating process, an immediate-release FDC tablet of valsartan and pravastatin was prepared using the wet granulation, drying, granulate screening, final blending, and tableting method. The tablet was mixed with valsartan $(160 \mathrm{mg})$, pravastatin $(40 \mathrm{mg})$, microcrystalline cellulose (45 mg), magnesium oxide (5 mg), low-substituted hydroxypropyl cellulose (40 mg), and distilled water $(24 \mathrm{mg})$ per tablet in the shear mixer from Nara Machinery Co. Ltd (NMG-1L. Tokyo, Japan) for $10 \mathrm{~min}$ for wet granulation, and then wet mixture were passed through a $1.7 \mathrm{~mm}$ screen to form granulate. Wet granules was transferred to trays and dried with controlled temperature $\left(60^{\circ} \mathrm{C}\right)$ (O'Hara Technologies, Inc., Richmond Hill, Canada) until the predefined loss on drying (LOD) of approximately $1.5 \% \mathrm{w} / \mathrm{w}$. Dry granulates were screened (Quadro Comil197S, Quadro Engineering, Canada) using a $990 \mu \mathrm{m}$ screen at 1,200 rpm. Afterwards, the screened granulates were mixed with superdisintegrant (croscamellose sodium, $45 \mathrm{mg}$ ) and lubricant (magnesium stearate, $5 \mathrm{mg}$ ) using a double cone blender (HS-DCM-10, Hansung F\&C Co., Korea) for 300 revolutions at $15 \mathrm{rpm}$. The final blend was compressed into target weight of $430 \mathrm{mg}$ under $10 \mathrm{kN}$ of compression force using a Piccola Nova tablet press (BD 4+4, Buenos Aires, Argentina). The coating was used for all trials (each 3,000 tablets) in a baffled pan coater (HCT Mini Hicoater, Freund Industrial Co. Ltd., Japan), with air flow rate at $1.0 \mathrm{~kg} / \mathrm{cm}^{2}$ and pan speed at $10 \mathrm{rpm}$. Tablets were coated using aqueous based Opadry $200^{\circledR}$ yellow coating system to a theoretical 3\% weight system.

\section{Product attribute study}

As shown in Table 1, the initial risk assessments showed that assay and degradation products were at a high risk of being affected by the coating process as final process of the overall manufacturing process for product production. Table 2 summarizes the risk assessment of the effects of the coating process variables (spray rate, pan speed, and inlet temperature), affecting quality attributes such as defect, coating efficiency, disintegration, and dissolution. ${ }^{7,8}$ Central composite face-centered design for response surface methodology was employed in this study. As shown in Table 3, seventeen batch formulations (each $0.85 \mathrm{~kg}$ )

were manufactured and evaluated for DoE study. Design Expert Software, Version 9.0.5.1 (Stat-Ease Inc., Minneapolis, MN, USA) was used to development a central composite face-centered for response surface design the relationship between three input factors related to coating process and four output drug product quality attributes.

\section{Disintegration test}

The disintegration time for the valsartan and pravastatin FDC tablet $(n=6)$ was tested following the standard 
USP method by disintegration test apparatus (DIT-200, Labfine, Korea).

\section{Dissolution study}

Dissoluition studies were modified by Trivedi et al, USP pravastatin sodium tablet and USP valsartan tablet. ${ }^{9-11}$ Dissolution studies (in vitro) of the tablets $(\mathrm{n}=8$ ) was carried out in USP Dissolution Apparatus 2 (the paddle type) employing paddle speed of $50 \mathrm{rpm}, 37 \pm 0.5^{\circ} \mathrm{C}$ for $60 \mathrm{~min}$ and water as dissolution medium. $5 \mathrm{~mL}$ sample were withdrawn at sampling time intervals $(5,10,15$, $30,45$, and $60 \mathrm{~min})$. The samples were filtered through a filtering rod $(0.45 \mu \mathrm{m})$ and analyzed at $230 \mathrm{~nm}$ using UV monitor (1200 series, Photo-Diode Array UV/ Vis detector, Agilent Technologies, USA) and HPLC (Agilent Technologies, 1200 series, USA) column (Phenomenex Synergi Polar RP, $150 \mathrm{~mm} \times 4.6 \mathrm{~mm}, 4 \mu \mathrm{m}$ ).

\section{Defects}

The samples of each batch were evaluated for the percentage defects. A defect was explained as any instance where the space between coating gun and tablet was distant, and the tablet core was exposed. Defects could include peeling, sticking, picking, chipping, or pin holes in the coating. ${ }^{7}$ The defects were evaluated by visual inspection of 100 tablets, three times per batch, and by calculating the average value of the results.

\section{Coating efficiency}

Tablets were coated with opadry $200^{\circledR}$ to a theoretical weight gain of $3 \%$. In this experiment, coating efficiency was evaluated by calculating the tablet weight before and after coating process.

\section{Statistical analysis and optimization}

Data were performed to generate the study design and the response surface plots using Design Expert software. The best fitting model was selected based on comparisons of several statistical parameters (the coefficient of variation (CV), coefficient of determination (R2) and adjusted coefficient of determination (adjusted R2) including $\mathrm{F}$ test and $\mathrm{P}$ values $(p<0.05))$. The relationship between the dependent and independent variables was further elucidated using response surface plots.

\section{RESULTS AND DISCUSSION \\ Preliminary study evaluation}

Valsartan and pravastatin FDC tablet is a film coated tablet. Valsartan and pravastatin FDC tablet was prepared by the following method: wet granulation, drying, sieving, blending, and tableting, and coating. Generally, direct compression, dry granulation, or wet granulation can be used for preparation of granulates prior to the compression and coating stage. ${ }^{12}$ Valsartan and pravastatin FDC tablet was selected a wet granulation method using water to improve powder flowability. In previous the DoE approach for wet granulation and tablet compression ( $0.85 \mathrm{~kg}$ lab-scale), granulating water $(60 \mathrm{~g})$, granulating time $(8 \mathrm{~min})$, and agitator speed $(200 \mathrm{rpm})$ for wet granulation and main compression force $(12 \mathrm{kN})$, press speed $(20 \mathrm{rpm})$, and feeder speed $(20 \mathrm{rpm})$ for tablet compression were optimal for the tablet having good blend uniformity, uniformity of dosage unit, and assay, etc. ${ }^{13,14}$ The DoE study for coating process was performed to identify the range of coating conditions using spray rate, pan speed, and inlet temperature.

\section{Evaluation of the coating process}

The quality target product profile (QTPP) based on the properties of a drug product is an essential element of a QbD approach. The CQAs having all properties of the desired product quality from the QTPP could be impacted by all of the attributes of the input materials and apparatus affecting the quality of coating process step during pharmaceutical development. ${ }^{6,15}$ For example, the fill level, spray rate, average weight gain, and pan speed in the tablet coating process are important because they affect coating uniformity, coating color development, defects, glass, and disintegration time., ${ }^{4,7}$ The mixing time, mixing speed, and amount in the coating suspension and atomization pressure are also potential CPPs for coating process. ${ }^{8}$ Accordingly, the parameters (spray rate, pan speed, and inlet temperature) for the coating process constituted the focus of the DoE in the study because they can affect the product CQAs of defects, coating efficiency, disintegration time, and dissolution. The assay and degradation product in the coating process were not identified by this DoE study because the friability of uncoated tablet was appropriately controlled by a previous step, i.e. compression process and the dwell time of coating is very short (about 1-2 h).

Film coating is commonly used for the protection of light, temperature, and moisture. ${ }^{11}$ The opadry $200^{\circledR}$ coating system was selected owing to the possibility of lactonization and oxidation of pravastatin by moisture and temperature. ${ }^{17,18}$ Two impurities of oxidation impurity and lactone by oxidation and lactonization were analyzed and managed by conduct of a USP pravastatin sodium tablet Related compounds (Oxidation impurity and pravastatin lactone). ${ }^{10,11}$ We have studied to identify the concentration of opadry ${ }^{\circledR} 200$ in coating process according to the manufacturer's instructions. Using the 
selected concentration (15\%), the suitability of the critical parameters (spray rate, pan speed, and inlet temperature) of the coating process on valsartan and pravastatin FDC tablet manufacturing was confirmed by seventeen 3,000 tablets lab-scale studies. The initial risk assessment of all process variables for the DoE study was identified form low to high based on experience and knowledgement of team member. ${ }^{19}$ The high risk in the coating process of valsartan and pravastatin FDC tablets led us to select spray rate, pan speed, and inlet temperature affecting defects, coating efficiency, disintegration time, and dissolution as CQAs (Table 2 and 3). In 2006, the Product Quality Research Institute investigated that coating suspension spray rate, pan rotation speed, exhaust air temperature and product bed temperature in the coating process are anticipated to be the most important factors. ${ }^{8}$

The experimental results for the factors and responses are presented in Table 3 . The results showed that defects varied from 1.2 to $100.0 \%$, coating efficiency from 55.7 to $89.4 \%$, disintegration time from 212.1 to $234.7 \mathrm{sec}$, and mean dissolution (f2) of valsartan and pravastatin from 57.5 to 65.1 . The spray rate and inlet temperature of the selected three independent factors was importantly affected in the quality attributes of defect, disintegration time, and mean dissolution. The pan speed and inlet temperature of the selected three independent factors was also affected in the quality attributes of coating efficiency.

As shown in the main effect plot (Figure 1A), spray rate and inlet temperature area more significant factor than pan speed affecting defect in the coating process. The main effect plot (Figure 1A) indicated that when spray rate and inlet temperature increased from 2.7 to $5.5 \mathrm{~g} / \mathrm{min}$ and from 55 to $75^{\circ} \mathrm{C}$, defect was found to increase regardless of pan speed, owing to overwetting on too much water in the tablet surface. ${ }^{7}$ The number of defects also increased under the interaction of spray rate and inlet temperature. Coating trials 8 and 14 appeared almost 100\% defects. These results occurred due to overwetting by a combination of spray rate, pan speed, and inlet temperature. ${ }^{7}$ By Figure $1 \mathrm{~A}$, it can be seen that coating with spray rate (the range of 2.7 to $3.4 \mathrm{~g} / \mathrm{min}$ ) and inlet temperature (the range of 55 to $75^{\circ} \mathrm{C}$ ) corresponds to observation of greater than $5 \%$ defects (Table 3). As shown in the analysis of variance (ANOVA) results for the design space of the selected model Table 4, the most significant factor affecting defect was spray rate and inlet temperature in the coating process. The selected model (Table 4 ) indicated that the effect of spray rate and inlet temperature $(\phi \leq 0.0001)$ on defect is significant, with $p<0.05$. In addition, lack of fit was not significant $(p=0.117)$ relative to the pure error. ${ }^{20}$ Coating efficiency was significantly influenced by pan speed and inlet temperature. The main effect plot (Figure 1B) indicated that when pan speed decreased from 8 to 24 in the inlet temperature (the range of 60 to $65^{\circ} \mathrm{C}$ ), coating efficiency of $100 \%$ was observed. Coating efficiency of batches $2,3,7,8,9,11,14,15$, and 16 having pan speed $(24 \mathrm{rpm})$ or inlet temperature $\left(75^{\circ} \mathrm{C}\right)$ demonstrated unacceptable results (55.71-78.71\%) based on the acceptance criteria $(>80 \%)$ (Table 3). As shown in the ANOVA results of the adjusted model including center points in Table 4, the selected model was significant $(p=0.0006)$, and lack of fit was not significant $(p=0.2983)$. In general, the rates of spray rate, inlet temperature and pan speed are the most important factors on tablet coating performances. ${ }^{21}$

Disintegration time for all coating trials were less than 4 min. The mean disintegration times of valsartan $\left(\right.$ Diovan $\left.^{\circledR}\right)$ and pravastatin $\left(\right.$ Mevalotin ${ }^{\circledR}$ ) were $<4$ min. So, the valsartan and paravastatin FDC tablet was established by the disintegration time of $<4$ min. The disintegration time of all batches demonstrated acceptable results $(212.17-234.75 \mathrm{sec})$ based on the acceptance criteria ( $<4 \mathrm{~min}$ ) (Table 3). Unless extreme coating conditions were used, the results of disintegration time were similarly observed. ${ }^{7}$ As the main effect plot (Figure 1C), the average values of disintegration time for coating process were $4.1 \mathrm{~g} / \mathrm{min}$ of spray rate and $16 \mathrm{rpm}$ of pan speed. As shown in the ANOVA results of the adjusted model including center points in Table 4, the selected model was significant $(p=0.0031)$, and lack of fit was not significant $(p=0.1182)$. Disintegration time was equivalent except for extreme coating condition of factors. $^{7}$

The dissolution similarities of valsartan and pravastatin were significantly influenced by spray rate and inlet temperature (Figure 1D). The main effect plots (Figure 1D) indicated that when spray rate and inlet temperature decreased from 5.5 to $2.7 \mathrm{~g} / \mathrm{min}$ and from 75 to $55^{\circ} \mathrm{C}$, dissolution rate was increased. However, the dissolution similarities of all batches demonstrated acceptable results (57.54-65.17) based on the acceptance criteria (f2 $\geq 55)$ (Table 3). As shown in the ANOVA results of the adjusted model including center points in Table 4, the selected model was significant, with $p=0.0057$ for valsartan and pravastatin. Moreover, lack of fit was not significant $(p=0.4824)$.

\section{Development of design space and control strategy}

For the design space development, the difference and a ratio of predicted and adjusted regression coefficient 


\begin{tabular}{|c|c|c|c|c|}
\hline \multirow[t]{2}{*}{ Process Step } & \multicolumn{4}{|c|}{ Drug Product CQAs } \\
\hline & Assay & Content uniformity & Dissolution & Degradation products \\
\hline Mixing \&wet granulation & Low & Low & High & Low \\
\hline Drying & Low & Low & Medium & Medium \\
\hline Granulate screening & Low & Low & High & Low \\
\hline Final blending & Low & Medium & Low & Low \\
\hline Tablet compression & Medium & High & High & Medium \\
\hline Coating & Medium & Low & Low & Medium \\
\hline
\end{tabular}

Table 2: Design of the central composite face-centered DoE to study coating process variables

\begin{tabular}{|c|c|c|c|c|c|}
\hline \multirow{2}{*}{\multicolumn{3}{|c|}{$\begin{array}{c}\text { Factors: Process parameter } \\
-1 \\
0\end{array}$}} & \multicolumn{3}{|c|}{ Range and Levels } \\
\hline & & & +1 & & \\
\hline A & \multicolumn{2}{|c|}{ Spray rate $(\mathrm{g} / \mathrm{min})$} & 2.7 & 4.1 & 5.5 \\
\hline B & \multicolumn{2}{|c|}{ Pan speed (rpm) } & 8 & 16 & 24 \\
\hline C & \multicolumn{2}{|c|}{ Inlet temperature $\left({ }^{\circ} \mathrm{C}\right)$} & 55 & 65 & 75 \\
\hline \multicolumn{2}{|r|}{ Responses } & Goal & \multicolumn{3}{|c|}{ Acceptable ranges } \\
\hline $\mathrm{Y}_{1}$ & Defects (\%) & Minimize & \multicolumn{3}{|c|}{$<5 \%$} \\
\hline $\mathrm{Y}_{2}$ & Coating efficiency (\%) & Maximize & \multicolumn{3}{|c|}{$>80 \%$} \\
\hline $\mathrm{Y}_{3}$ & Disintegration time (min) & Minimize & \multicolumn{3}{|c|}{$<4 \min$} \\
\hline $\mathrm{Y}_{4}$ & $\begin{array}{l}\text { Mean dissolution similarity of } \\
\text { valsartan and pravastatin ( } \mathrm{f} 2 \text { ) }\end{array}$ & Maximize & \multicolumn{3}{|c|}{$\geq 55$ (f2) } \\
\hline
\end{tabular}

\section{Table 3: Experimental results of the central composite face-centered DoE to study coating process variables}

\begin{tabular}{|c|c|c|c|c|c|c|c|}
\hline \multirow{3}{*}{$\begin{array}{l}\text { Batch } \\
\text { No. }\end{array}$} & \multicolumn{3}{|c|}{ Factors: Process variables } & \multicolumn{4}{|c|}{ Responses } \\
\hline & $\begin{array}{l}\text { A: } \\
\text { Spray } \\
\text { rate }\end{array}$ & $\begin{array}{c}\text { B: } \\
\text { Pan } \\
\text { speed }\end{array}$ & $\begin{array}{c}\text { C: } \\
\text { Inlet } \\
\text { temperature }\end{array}$ & $\begin{array}{c}\text { Y: } \\
\text { Defécts }\end{array}$ & $\begin{array}{c}\mathrm{Y}: \\
\text { Coating } \\
\text { efficiency }\end{array}$ & $\begin{array}{c}\mathrm{Y}_{3}: \\
\text { Disintegration } \\
\text { time }\end{array}$ & $\begin{array}{c}\text { Y: } \\
\text { Mean } \\
\text { dissolution } \\
\text { similarity of } \\
\text { valsartan and } \\
\text { pravastatin }\end{array}$ \\
\hline & $(g / \mathrm{min})$ & $(\mathrm{rpm})$ & $\left({ }^{\circ} \mathrm{C}\right)$ & $(\%)$ & $(\%)$ & $(\min )$ & (f2) \\
\hline 1 & 4.1 & 16 & 65 & 4.21 & 87.98 & 229.41 & 61.22 \\
\hline 2 & 4.1 & 16 & 75 & 4.78 & 78.71 & 228.74 & 59.86 \\
\hline 3 & 5.5 & 8 & 75 & 31.20 & 75.93 & 215.87 & 57.54 \\
\hline 4 & 5.5 & 16 & 65 & 38.91 & 81.23 & 219.98 & 59.23 \\
\hline 5 & 4.1 & 16 & 55 & 40.78 & 89.21 & 217.44 & 63.54 \\
\hline 6 & 4.1 & 8 & 65 & 15.56 & 88.97 & 212.17 & 59.96 \\
\hline 7 & 2.7 & 24 & 75 & 2.74 & 55.71 & 225.83 & 60.24 \\
\hline 8 & 5.5 & 24 & 55 & 100.00 & 60.13 & 225.11 & 61.74 \\
\hline 9 & 2.7 & 16 & 65 & 1.23 & 77.98 & 226.98 & 62.55 \\
\hline 10 & 4.1 & 16 & 65 & 4.14 & 84.72 & 229.17 & 59.91 \\
\hline 11 & 5.5 & 24 & 75 & 14.78 & 59.93 & 231.24 & 60.43 \\
\hline 12 & 4.1 & 16 & 65 & 5.71 & 89.41 & 230.55 & 59.82 \\
\hline 13 & 2.7 & 8 & 55 & 6.92 & 82.14 & 219.83 & 65.17 \\
\hline 14 & 5.5 & 8 & 55 & 98.81 & 65.33 & 213.78 & 60.23 \\
\hline 15 & 2.7 & 8 & 75 & 2.41 & 67.78 & 225.81 & 62.75 \\
\hline 16 & 2.7 & 24 & 55 & 8.74 & 75.74 & 234.75 & 63.97 \\
\hline 17 & 4.1 & 24 & 65 & 5.13 & 85.13 & 233.71 & 62.28 \\
\hline
\end{tabular}




\section{Table 4: ANOVA results of the selected model}

\begin{tabular}{|c|c|c|c|c|c|c|}
\hline Source & $\begin{array}{l}\text { Sum of } \\
\text { squares }\end{array}$ & $\mathbf{d f} \mathbf{a}^{a}$ & $\begin{array}{l}\text { Mean } \\
\text { square }\end{array}$ & F-value & $\begin{array}{c}p \text {-value } \\
\text { (Probe > F) }\end{array}$ & $\begin{array}{c}\text { Regression } \\
\text { coefficient }\end{array}$ \\
\hline \multicolumn{7}{|l|}{ Defects } \\
\hline Model & 1536.47 & 9 & 1737.39 & 51.64 & $<0.0001$ & 0.9852 \\
\hline Lack of fit & 233.90 & 5 & 46.78 & 58.23 & 0.1170 & - \\
\hline \multicolumn{7}{|c|}{ Coating efficiency } \\
\hline Model & 1905.24 & 9 & 211.69 & 16.98 & 0.0006 & 0.9562 \\
\hline Lack of fit & 75.73 & 5 & 15.15 & 2.63 & 0.2983 & - \\
\hline \multicolumn{7}{|c|}{ Disintegration time } \\
\hline Model & 501.69 & 3 & 167.23 & 7.84 & 0.0031 & 0.6440 \\
\hline Lack of fit & 276.45 & 11 & 25.13 & 54.24 & 0.1182 & - \\
\hline \multicolumn{7}{|c|}{$\begin{array}{l}\text { Mean dissolution similarity of } \\
\text { valsartan and pravastatin }\end{array}$} \\
\hline Model & 55.31 & 9 & 6.15 & 8.17 & 0.0057 & 0.9130 \\
\hline Lack of fit & 4.05 & 5 & 0.81 & 1.33 & 0.4824 & - \\
\hline
\end{tabular}

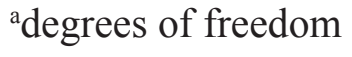
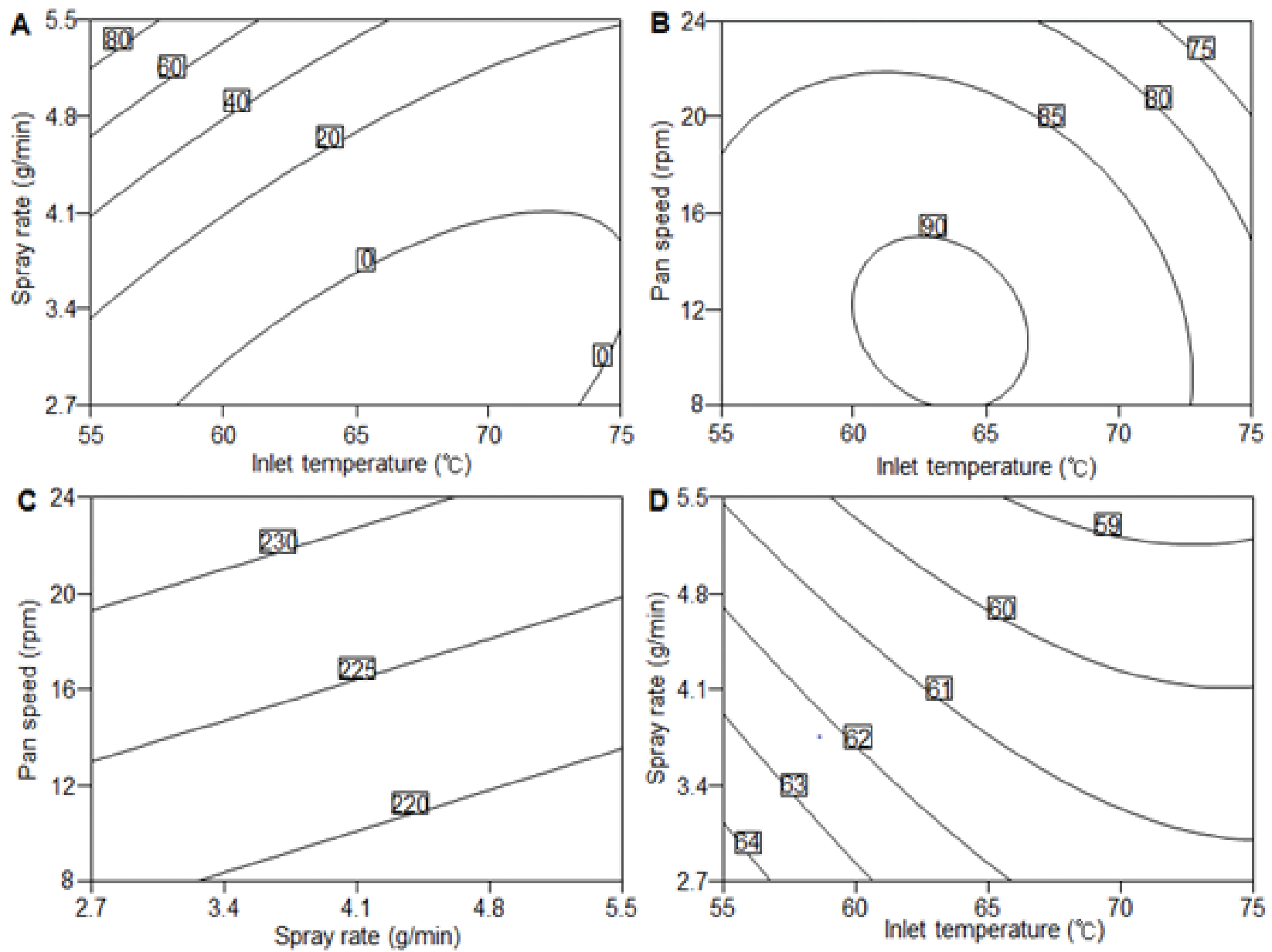

Figure 1: Main effect of spray rate, pan speed, and inlet temperature on (A) defects (\%), (B) Coating efficiency (\%), (C) Disintegration time (sec), (D) Mean dissolution similarity of valsartan and pravastatin (f2). 


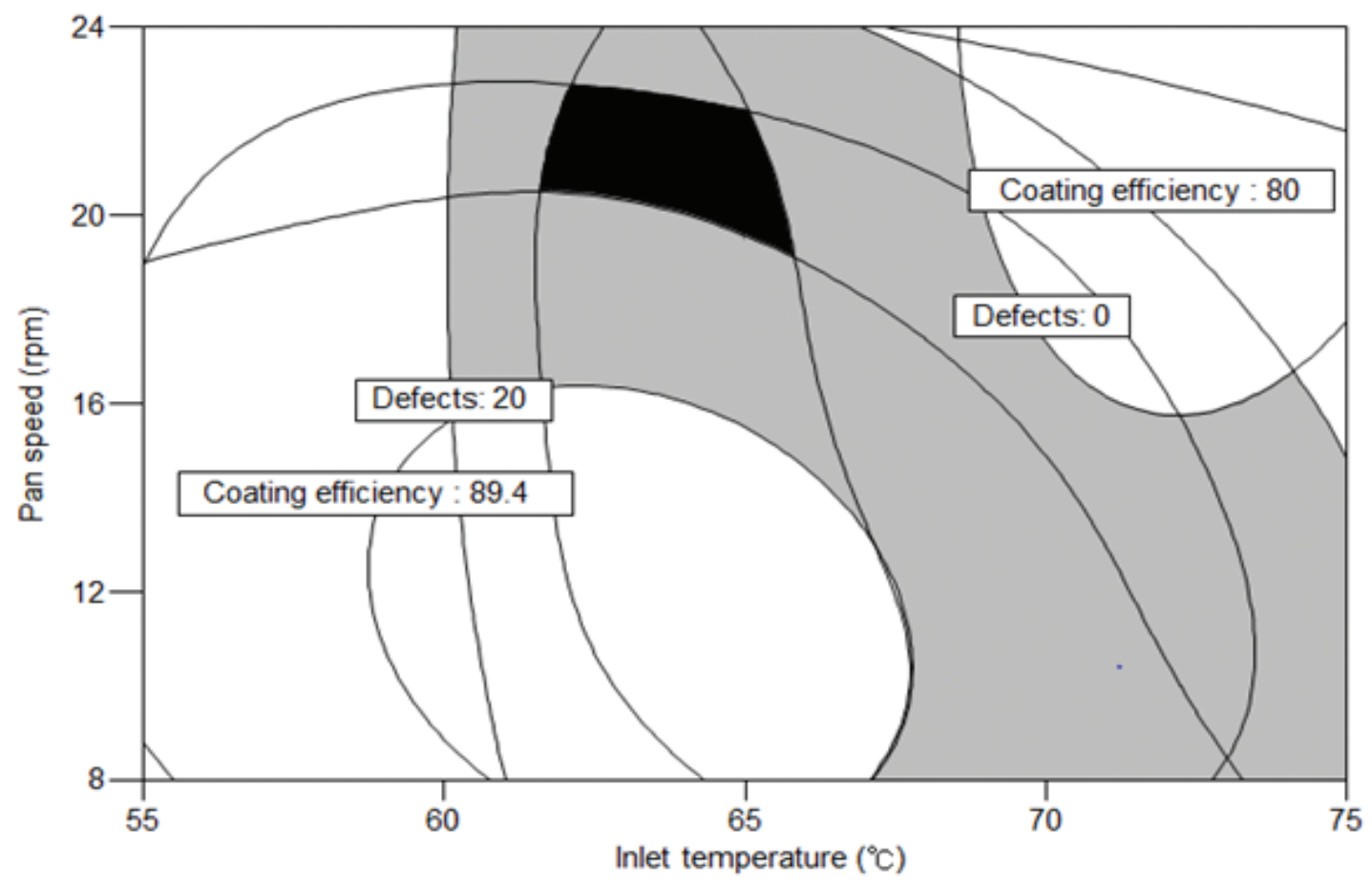

Figure 2: Design space for the coating process of valsartan and pravastatin FDC tabletat spray rate $(4.1 \mathrm{~g} / \mathrm{min})$.

$\left(\mathrm{R}^{2}\right)$ should beless than 0.2 and greater than 4 , respectively. ${ }^{22}$ Our results showed that the difference and ratio of the predicted and adjusted $\mathrm{R}^{2}$ followed this rule at minimum (0.0483 and 5.74) and maximum (0.1278 and $24.180)$ values for all responses. To secure the robustness of the process, a design space with a $95 \%$ confidence interval (CI) on the mean values of responses was drawn (Figure 2). The design space was established in the region of black color for the most successful operating ranges for the coating process. A tablet made with the spray rate $(4.1 \mathrm{~g} / \mathrm{min})$, inlet temperature $\left(65^{\circ} \mathrm{C}\right)$ and pan speed $(20 \mathrm{rpm})$ would reach the desired percentage of the minimized defect and maximized coating efficiency (Figure 2). If tablets are manufactured within condition of black part, a desirable outcome can be anticipated.

Spray rate and inlet temperature were a critical process parameters for the minimum number of defects and coating efficiency. Accordingly, the ranges of the independent variables were well defined as pan speed (18-23 rpm), inlet temperature $\left(63-67^{\circ} \mathrm{C}\right)$ with spray rate $(4.1 \mathrm{~g} / \mathrm{min})$ had no significant impact on defect, coating efficiency, disintegration time and dissolution. The point in the design space is not changed and can be built by the desired quality for the product.

These results confirmed that robust performance was observed over operating ranges of factors (spray rate, pan speed and inlet temperature). The control strategy for the coating process of valsartan and pravastatin FDC tablets should maintain the in-process coating attributes of defect, coating efficiency, disintegration time and dissolution within the required ranges. Based on the results of the DoE study in lab-scale, the factor and process variables for the coating process should be set and optimized within the acceptance criteria for scale-up.

\section{ACKNOWLEDGEMENTS}

This research was supported by a Kyungsung University Research Grant in 2016. This research was also (partially) supported by Busan metropolitan city grant (Busan Brain 21) in 2016.

\section{CONFLICT OF INTEREST}

The authors report no conflicts of interest.

\section{REFERENCES}

1. Cole GC. Pharmaceutical Coating Technology, London: Taylor and Francis Ltd. 1998;6-52.

2. Porter SC, Coating of pharmaceutical solid-dosageforms. Pharm Tech. 1980;4:66-9.

3. Dubey A, Boukouvala F, Keyvan G, Hsia R, Saranteas K, Brone D, Misra T. Improvement of tablet coating uniformity using a quality by design approach. AAPS Pharm Sci Tech. 2012;13:231-46. http://dx.doi.org/10.1208/s12249011-9723-x PMid:22232020 PMCid:PMC3299457.

4. Dubey A, Hsia R, Saranteas K, Brone D, Misra T, Muzzio JF, Effect of speed, loading and spray pattern on coating variability in a pan coater. Chem Eng Sci. 2011;66:5107-115 http://dx.doi.org/10.1016/j.ces.2011.07.010.

5. Prpicha AT. am Endea M, Katzschnerb T, Lubczykb V, Weyhersb $H$, Bernhardb G. Drug product modeling predictions for scale-up of tablet film 
coating—A quality by design approach. Compu Chem Eng. 2010;34:1092-7 http://dx.doi.org/10.1016/j.compchemeng.2010.03.006.

6. International Conference on Harmonisation (ICH) guideline. Q8 Pharmaceutical development; 2009.

7. Teckoe J, Mascaro T, Farrell PT, Rajabi-Siahboomi RA. Process optimization of a novel immediate release film coating system using QbD principles. AAPS Pharm Sci Tech. 2013;14(2):531-40. http://dx.doi.org/10.1208/s12249-0139935-3 PMid:23483430 PMCid:PMC3666010.

8. Product quality research institute (PQRI). Process robustness-a PQRI white paper. Pharm Engine. 2006;26(6):1-11.

9. Trivedi GS, Raj HA, Jain VC. First derivative spectroscopic method for simultaneous estimation of pravastatin and valsartan in synthetic mixture. Asian J Pharm Tech. 2015;5:83-90. http://dx.doi.org/10.5958/22315713.2015.00013.6.

10. The United States Pharmacopeia USP38, The National Formulary NF33, United States Pharmacopeial Convention, Inc. Pravastatin sodium tablet. 2015, page 4966.

11. The United States Pharmacopeia USP38, The National Formulary NF33, United States Pharmacopeial Convention, Inc. Valsartan tablet. 2015, page 5743.

12. Kondeti RR, Mulpuri KS, Koganti M, Rathnam Dr.G. A comparative study on different methods of granulation on tablet properties. Asian Pharm Tech. 2014;2:70-7.

13. Kim KM, Kang JS. Design of experiments for tablet compression of valsartan and pravastatin fixed-dose combination tablet. Asian J Chem. 2016;28:2539-44. http://dx.doi.org/10.14233/ajchem.2016.20079 http://dx.doi.org/10.14233/ ajchem.2016.20115
14. Kim KM, Kim GT, Kang JS. Design of experiments for wet granulation of valsartan and pravastatin fixed-dose combination tablet. Asian J. Chem. 2016;28:2759-63. http://dx.doi.org/10.14233/ajchem.2016.20079 http:// dx.doi.org/10.14233/ajchem.2016.20115.

15. Bajaj S, Singla D, Sakhuja N. Stability testing of pharmaceutical products. J Appl Pharm Sci. 2012;2:129-38.

16. Sah AK, Jangdey MS, Daharwal SJ. Tablet Coating Technology : An Overview. Asian J Pharm Tech. 2014;4:83-97.

17. Kocijana A, Graheka R, Zupančič-Kraljb L. Identification of an impurity in pravastatin by application of collision-activated decomposition mass spectra. Acta Chim Slov. 2006;53:464-8.

18. Brain-Isasi S, Requena C, Alvarez-Lueje A. Stability study of pravastatin underhydrolytic conditions assessed by HPLC. J Chil Chem Soc. 2008;52:1684-8.

19. Yu LX. Pharmaceutical quality by design: product and process development, understanding, and control. Pharmaceut Res. 2008;25:781-91. http://dx.doi. org/10.1007/s11095-008-9667-3 http://dx.doi.org/10.1007/s11095-007-95111 PMid:18185986.

20. Akala EO, Adesina S, Ogunwuyi O. Computer optimization of biodegradable nanoparticles fabricated by dispersion polymerization. Int $\mathrm{J}$ Environ Res Public Health. 2016;13:47 http://dx.doi.org/10.3390/ijerph13010047 PMid:26703678 PMCid:PMC4730438.

21. Patel JK, Shah AM. Aqueous-based Film coating of Tablets: Study the Effect of Critical Process Parameters. Int J Pharm Tech Res. 2009;1:235-40.

22. Nkuzinna OC, Menkiti MC, Onukwuli OD, Mbah GO, Okolo BI, Egbujor MC, et al. Application of factorial design of experiment for optimization of inhibition effect of acid extract of Gnetumafricana on copper corrosion. Nat Resour. 2014;4:299-307.

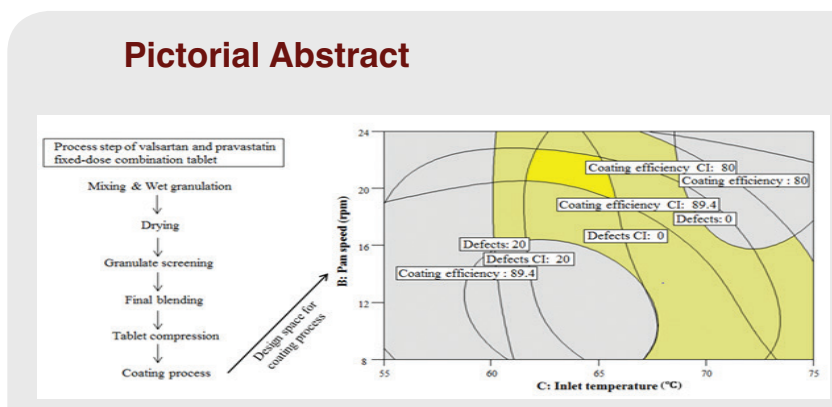

\section{About Authors}

\section{SUMMARY}

- Valsartan and pravastatin fixed-dose combination tablet was investigated the ranges of critical process parameters (spray rate, pan speed, and inlet temperature) in the coating process.

- Spray rate $(4.1 \mathrm{~g} / \mathrm{min})$, pan speed (from 18 to 23 rpm), and inlet temperature (from 63 to 67 oC) in the coating process were optimized for valsartan and pravastatin tablet fixed-dose combination tablet.

- The wide process ranges of operation for spray rate, pan speed, and inlet temperature will produce high quality products

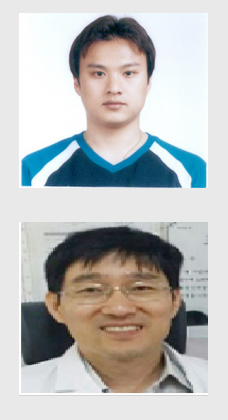

Kangmin Kim: Is an Assistant at the Department of pharmacy in the kyungsung university. His present research focused on the Formulation development and stabilization of chemicals \& biopharmaceuticals

Jaeseon Kang: Is a professor at the Department of pharmacy in the kyungsung university. His present research focused on the biopharmacy and biomaterials development from probiotic

Cite this article: Kim K, Kang JS. Design of Experiments for Coating Process of Valsartan and Pravastatin Fixeddose Combination Tablet. Indian J of Pharmaceutical Education and Research. 2017;51(1):128-35. 